\title{
Design of an Integrated DC-Link Structure for Reconfigurable Integrated Modular Motor Drives
}

\author{
Abdalla Hussein Mohamed, Hendrik Vansompel and Peter Sergeant, Senior Member, IEEE
}

\begin{abstract}
In this paper, a DC-link structure feasible for integration with the circumscribing polygon modular integrated drives is proposed. The proposed DC-link structure combines both the DC-link capacitors and the busbar together and integrates them with the machine and the converter modules without increasing the outer diameter of the integrated machine/converter structure. A generic design methodology for the proposed DC-link structure is provided and applied on a reconfigurable fifteen stator coils concentrated winding axial flux machine for all its possible phase configurations. The design methodology presented in this paper involves the determination of the required DC-link capacitance and the multi-physics design of the bus-bar. The parasitics of the bus-bar part of the proposed DC-link structure are evaluated using electromagnetic FEM models and their influence on the DC-link waveforms is evaluated. Due to the expected high ambient temperature inside an integrated drive, electromagnetic and CFD models are developed for the proposed DC-link structure to evaluate the loss density and the temperature distribution of the bus-bar to ensure reliable operation. An experimental setup is built to validate the design methodology.
\end{abstract}

Index Terms-Integrated modular drives, DC link capacitors, DC link bus-bar, Wide Bandgap converters, Parasitic inductance, Bus-bar thermal modelling, Bus-bar electromagnetic modelling, DC-link voltage spike.

\section{INTRODUCTION}

$\mathbf{I}$ NTEGRATED modular motor drives (IMMDs) represent a modularized and physically integrated machine, power converter and DC-link structure [1]. IMMDs provide the advantages of high fault tolerance and high power density compared to the conventional drives [2]- [3]. The high fault tolerance results from the redundancy and the flexibility in dividing and configuring the stator modules to maximize the torque that can be generated at a certain fault. The high power density and compactness of the drive results from the elimination of the converter separate housing and the cables connecting the converter to the machine [4].

Manuscript received Month $\mathrm{xx}, 2 \mathrm{xxx}$; revised Month $\mathrm{xx}$, xxxx; accepted Month $x, x x x x$. This research is part of the ModulAr SBO project funded and supported by Flanders Make vzw, the strategic research centre for the manufacturing industry. Abdalla $\mathrm{H}$. Mohamed, $\mathrm{H}$. Vansompel and P. Sergeant are with the Department of Electromechanical, Systems and Metal Engineering, Ghent University, 9000 Ghent, Belgium, and Flanders Make @UGent - core lab EEDT-MP, Belgium (e-mail: Abdalla.Mohamed@UGent.be). Abdalla H. Mohamed is also with Electrical power department (EPE), Faculty of Engineering, Cairo University, Giza (e-mail:a.Hussien.Rashad@gmail.com)
Many challenges have to be met for the realization of an IMMD. Among these challenges, the small space available for the converter modules has to be efficiently utilized by optimal selection of the converter components especially, the DClink capacitor as it represents the bulkiest component in the converter module [5] beside the heatsink. One more challenge is the high thermal stresses that the converter switches and capacitors will be exposed to due to their close proximity to the major heat sources in the machine [6].

The small space and the thermal challenges of the integrated drives can be met by utilizing the wide bandgap (WBG) semiconductor devices such as the Gallium Nitride $(\mathrm{GaN})$ and Silicon Carbide $(\mathrm{SiC})$ in the implementation of the converter modules due to their lower losses, higher thermal conductivity, smaller package size for the same voltage and current rating compared to the Silicon (Si) devices [7]. Using WBG devices makes it possible to switch with higher frequency than the $\mathrm{Si}$ case which results in smaller DC-link capacitance [8].

IMMDs are classified according to the location of the power converter modules with respect to the machine housing and the stator elements into: axially stator iron mounted (ASM), radially stator iron mounted (RSM), axially housing mounted (AHM), radially housing mounted (RHM) [9] and circumscribing polygon $(\mathrm{CP})$ integration topology [10]. The RSM, ASM and CP provide a more compact integrated drive with higher cooling design challenges.

In this paper, a DC-link structure feasible for physical integration with $\mathrm{CP}$ modular integrated drives is proposed. This DC-link structure combines both the capacitors and the bus-bar. Besides the possibility of the physical integration with the integrated machine/converter structure, the proposed DClink structure in this paper provides four more advantages. The first one is that the proposed DC-link structure doesn't increase the outer diameter of the integrated machine/converter structure which results in a more compact integrated structure. The second one is that it has a small parasitic inductance from the capacitor terminals to the converter DC input terminals which reduces the voltage spike on the converter switches. The third one is that it has a relatively high inductance from the DC-source input terminals to the capacitor terminals which further smooths the current supplied from the DC-source reducing the electrical and the thermal stresses on it. The fourth one is that the bus-bar part is easy to manufacture and the capacitors are chosen off the shelf and no need for the time consuming and the expensive custom designed DC-link structure as proposed in [11].

The authors in [5]- [12]- [13] address the design of the 
DC-link capacitor for three phase drives with a single set of stator winding. The authors in [14]- [15] handle the influence of the pulse width modulation (PWM) carriers interleaving on the design of the capacitor of the three phase drives with dual stator winding. In [16], the authors illustrated the possibility of using carrier interleaving with IMMDs but no closed form generic design equations are given. In [?], the authors presented generic analytical design equations for the DC-link capacitors of the reconfigurable IMMDs. These equations are adopted in this paper.

The DC-link bus-bar connects the DC-source, the capacitors and the converter modules together [17]. In [18]- [19]- [20][21], the authors study the influence of the bus-bar geometry for three phase inverters implemented using commercial halfbridge modules on the value of the parasitic inductance. Lacking in literature, a comprehensive study for an integrated busbar structure feasible for IMMDs given their special structure and high ambient temperature.

In this study, a generic design methodology for the proposed DC-link structure feasible for reconfigurable modular integrated drives is provided and applied on a fifteen stator coils circumscribing polygon integrated axial flux drive. The design process presented in this paper involves the determination of the required DC-link capacitance for each configuration and the multi-physics design of the bus-bar. An electromagnetic FEM model and CFD model are developed for the proposed DC-link structure to ensure that the electrical and the thermal stresses on the components of the DC-link structure are within the rated values.

The electromagnetic FEM model is used to extract the DClink structure parasitics so that, the DC-link voltage spike can be estimated, and to compute the loss density distribution in the bus-bar. This loss density distribution is used as an input to a CFD model for the DC-link structure to compute the temperature distribution. In this way, both the electrical and the thermal stresses on the bus-bar can be evaluated to ensure reliable operation in the high ambient temperature environment of the integrated drive.

The paper is organized as follows: section II provides a brief description of the $\mathrm{CP}$ integrated drive for which the DClink structure is designed and analysed. In section III, the mechanical construction of the proposed DC-link structure is explained. Section IV discusses in detail the design of the proposed DC-link structure. The experimental setup and results are given in section $\mathrm{V}$ and then the conclusion is given in section VI.

\section{StRucture OF THE CP IMMD}

The integrated DC-link structure proposed in this paper is applied on an IMMD with fifteen stator coils with circumscribing polycon integration of the power converter modules [10]. Fig. 1 shows the construction of this CP integrated drive. The drive combines the electric machine, the power converter modules, the shared cooling structure and the DClink structure. The polygon shaped shared cooling structure with the converter modules mounted on top is illustrated in Fig. 2. Table I contains the main specifications of this integrated drive topology.

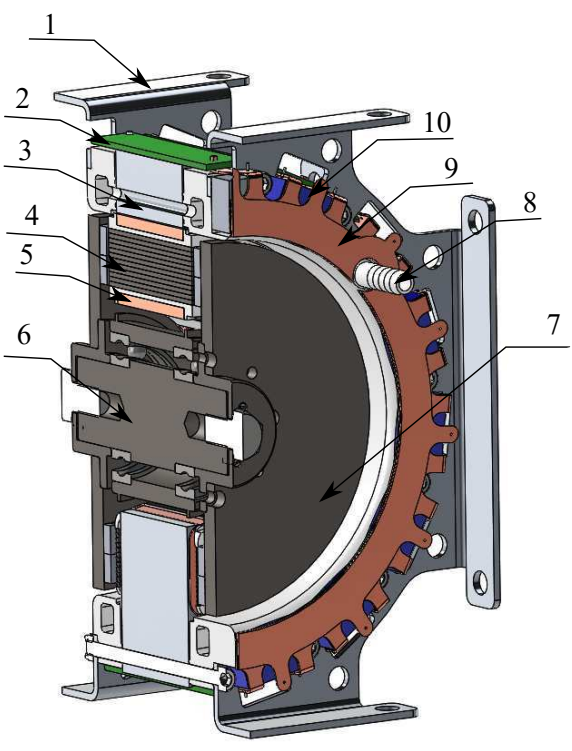

Fig. 1. A CP integrated drive: (1) Mounting structure, (2) Converter module PCB, (3) Cooling channel, (4) Core, (5) Winding, (6) Shaft, (7) Rotor disc, (8) Cooling fluid fitting, (9) DC-link bus-bar, (10) DC-link capacitor

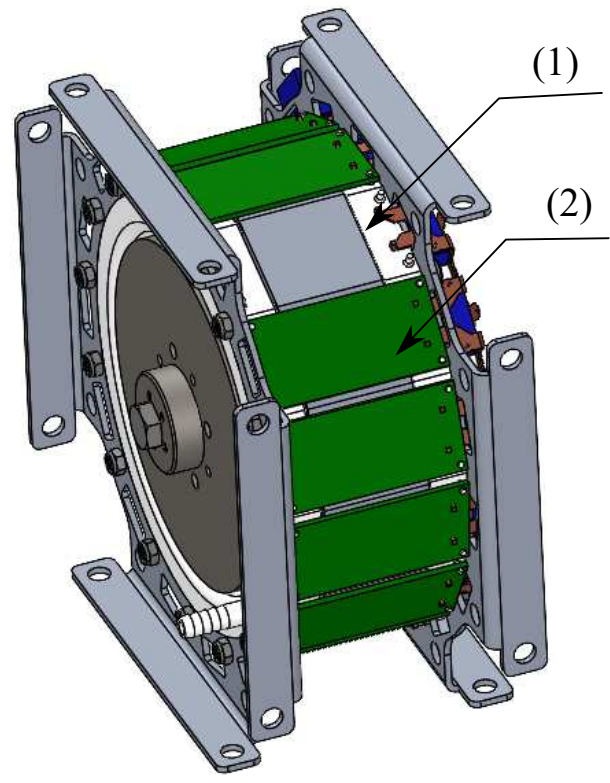

Fig. 2. The polygon shaped shared cooling structure with the converter PCB on top: (1) The polygon shared cooling structure, (2) Converter module $\mathrm{PCB}$

Each converter module has a size of $60 \times 40 \mathrm{~mm}^{2}$ and is capable of providing up to $1.13 \mathrm{~kW}$. The converter is implemented using GaN technology. Fig. 3 shows a picture for the implemented $\mathrm{GaN}$ based half-bridge module.

\section{Mechanical CONStRuction Of the integrated DC-LINK}

Fig. 4 shows the construction of the proposed DC-link structure. It consists of a ring shaped bus-bar with the DC-link capacitors arranged circumferentially pointing radially inward. In this way, the bus-bar and the capacitors are integrated with 
TABLE I

THE KEY SPECIFICATIONS OF THE INTEGRATED DRIVE

\begin{tabular}{|c|c|}
\hline Quantity & Value \\
\hline rated power $(\mathrm{kW})$ & 17 \\
rated speed $(\mathrm{rpm})$ & 2500 \\
\# pole pairs & 8 \\
\# slots & 15 \\
axial length $(\mathrm{mm})$ & 60 \\
outer diameter $(\mathrm{mm})$ & 190 \\
converter module size $\left(\mathrm{mm}^{2}\right)$ & $60 \times 40$ \\
\hline
\end{tabular}

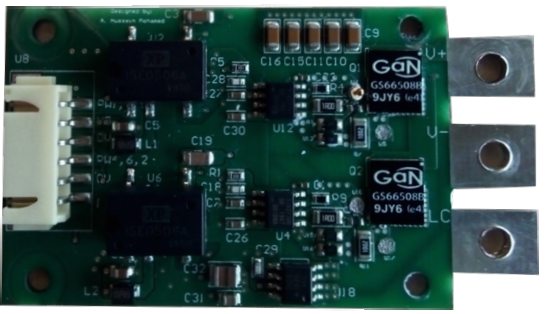

Fig. 3. The GaN based half-bridge module

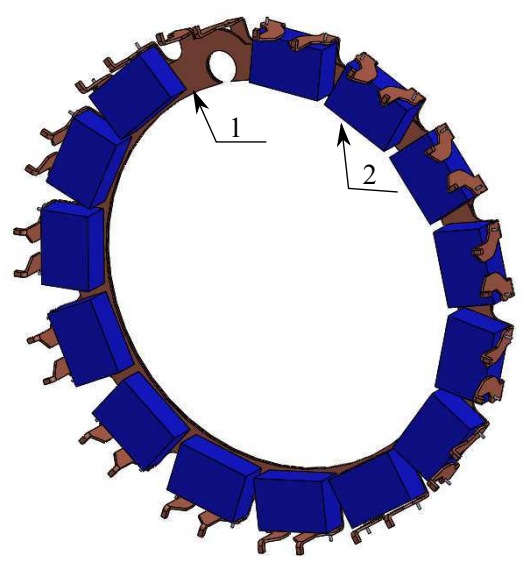

Fig. 4. The DC-link structure: (1) The bus-bar structure, (2) The DC-link capacitors

the machine/converter structure without increasing the outer diameter which enhances the compactness of the drive.

Fig. 5 shows an exploded view for the bus-bar part of the DC-link structure. It consists of a positive plate, a negative plate and an electrical insulation layer between them. Each plate has an input tab for the DC-source, a connection terminal for the module capacitor and a connection terminal for the converter input source. A short distance of $17.5 \mathrm{~mm}$ between the capacitor terminal and the converter DC-input terminal is achieved which results in a small $\mathrm{AC}$ parasitic inductance and hence small switches voltage spike. A relatively longer average distance of $115 \mathrm{~mm}$ between the DC-source input tab and the converter input terminal is achieved which results in a relatively greater DC parasitic inductance and hence a smoother DC-source current and smaller DC-source stress will result.

The conducting plates can be made of copper or aluminium.

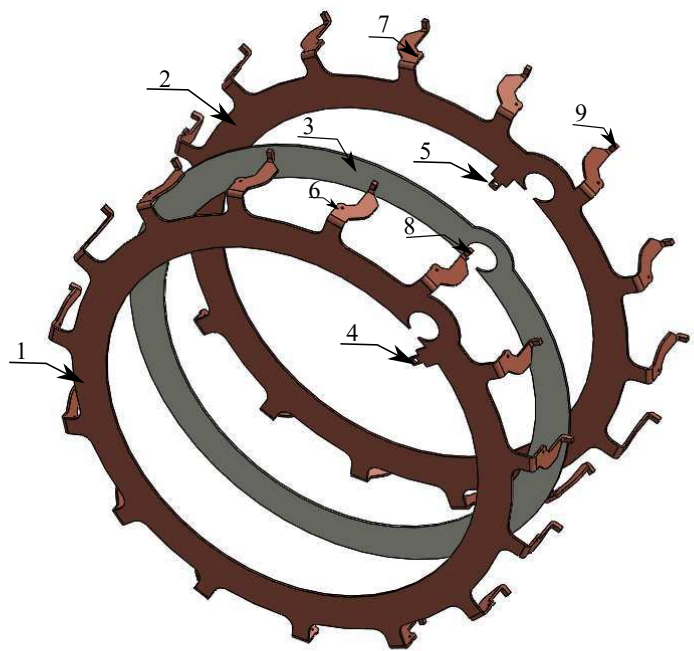

Fig. 5. DC-link bus-bar structure for a modular fifteen stator coils drive: (1) Positive plate, (2) negative plate, (3) insulation layer, (4) DC-input plus, (5) DC-input minus, (6) capacitor plus terminal, (7) capacitor minus terminal, (8) converter module plus input, (9) converter module minus input

TABLE II

PROPERTIES OF INSULATION MATERIALS

\begin{tabular}{|c|c|c|c|c|}
\hline Material & $E(\mathrm{kV} / \mathrm{mm})$ & $\epsilon_{r}$ & rated temperature $\left({ }^{\circ} \mathrm{C}\right)$ & $K_{t h}(\mathrm{~W} / \mathrm{m} . \mathrm{K})$ \\
\hline Kapton & 196 & 3.7 & 400 & 0.4 \\
Mylar & 295 & 3.3 & 105 & 0.14 \\
Nomex & $17-33$ & 1.6 & 220 & 0.157 \\
FR4 & 49 & 4.3 & 140 & 0.31 \\
\hline
\end{tabular}

Using aluminium plates results in a lighter drive due to the smaller mass density of aluminium compared to copper but higher loss and temperature will result due to the smaller electrical and thermal conductivity of the aluminium. The insulation layer can be made of kapton, mylar, nomex or epoxy glass (FR4). Table II contains the main properties of the insulation materials. Here, $E$ is the breakdown strength, $\epsilon_{r}$ is the relative permittivity and $K_{t h}$ is the thermal conductivity. As the maximum bus-bar temperature is limited by the rated temperature of the insulation layer, kapton represents the optimal choice from the thermal point of view.

\section{DESIGN OF THE DC-LINK STRUCTURE}

The design of the integrated DC-link structure involves the determination of the DC-link capacitors for each possible configuration of the modular drive and the multi-physics analysis of the mechanical outline of the integrated bus-bar part of the DC-link structure.

\section{A. Selection of the DC-link capacitors}

By proper DC-link voltage scaling and stator coils connection, the fifteen stator coils of the integrated drive in Fig. 1 can be configured to operate as three phase, five phase or fifteen phase drive [?]. In case of three phase operation, five stator coils are connected in series to form one phase as in Fig. 6. 


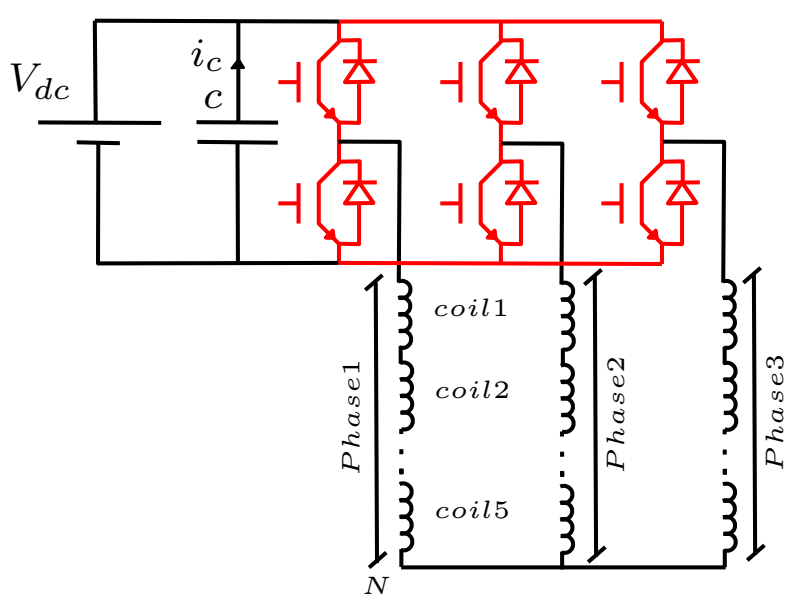

Fig. 6. The connection in case of three phase operation

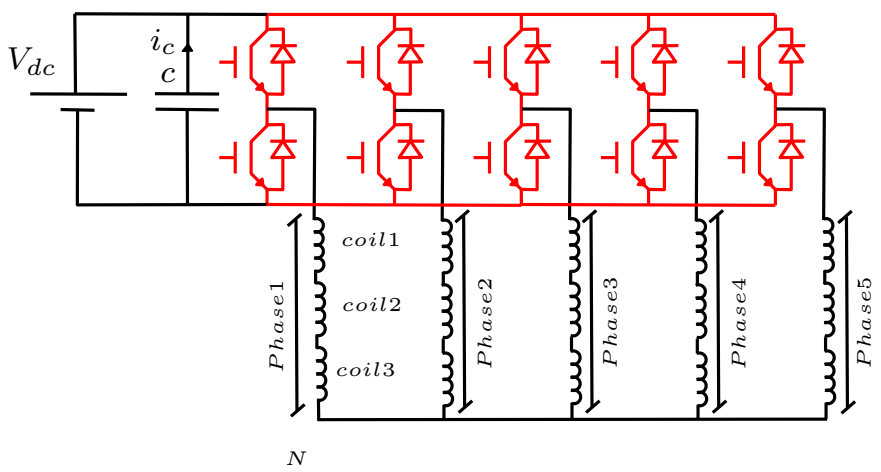

Fig. 7. The connection in case of five phase operation

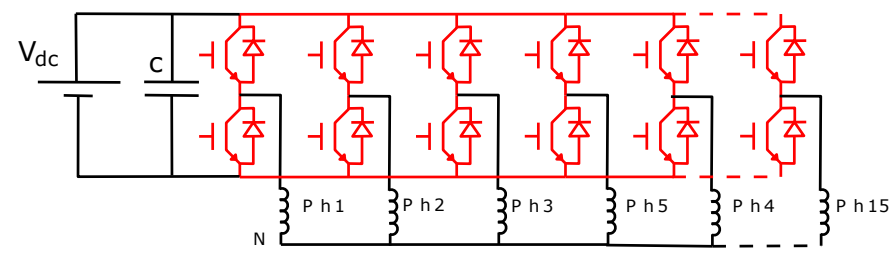

Fig. 8. The connection in case of fifteen phase operation with one common neutral

In case of five phase operation, three coils are in connected in series to form one phase as in Fig. 7. In case of fifteen phase operation, the stator coils can be connected to have one common neutral point as in Fig. 8, divided into five groups with three coils in each group as in Fig. 9 or divided into three groups with five coils in each group as in Fig. 10. For the connections in Fig. 9 and Fig. 10, the pulse width modulation carriers can be shifted by an interleaving angle $K$ to further reduce the DC-link current stress. Each configuration has its own Torque-speed and fault-tolerance characteristics.

Equations (1), (2) can be used to calculate the DC-link capacitor harmonic currents while (3) and (4) can be used to estimate the value of the needed DC-link capacitance [?]. The equations are valid for each possible configuration of the reconfigurable modular drives. The DC-link capacitance requirement of the reconfigurable drive in Fig. 1 is calculated for each configuration considering $400 \mathrm{~V}$ DC-link voltage in case

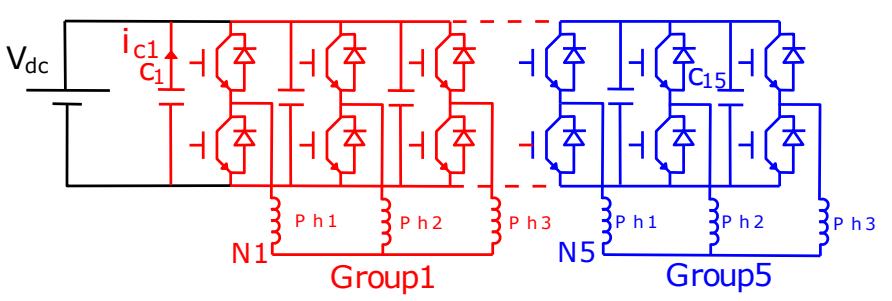

Fig. 9. The connection in case of fifteen phase divided as five groups with three phase in each group

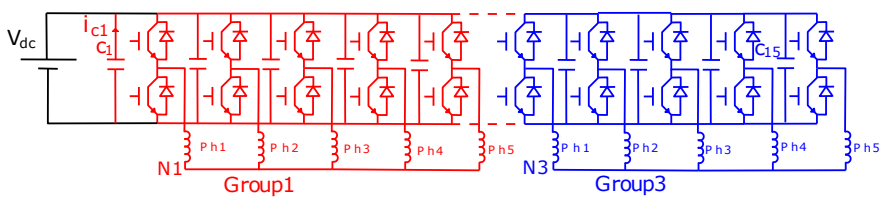

Fig. 10. The connection in case of fifteen phase divided as three groups with five phase in each group

of three phase operation. For the other configurations, the DClink voltage is adjusted to keep the phase current and power the same. The design is performed for $1 \% V_{\text {ppripple. Table III }}$ contains the calculated DC-link capacitance requirements per module for each configuration.

$$
\begin{aligned}
& i_{\text {ch }}(n, m)=\frac{i_{\text {linepeak }}}{2 \pi^{2}} \sum_{s=1}^{g} \sum_{h=1}^{N} \int_{y_{\min }}^{y_{\max }} f(x, y) d y d x \\
& \left\{\begin{array}{l}
\left.f(x, y)=\cos (x-\phi+n \theta) e^{i(m y+n x}\right) \\
y_{\min }=\frac{\pi}{2}(1-M \cos (x+n \theta))+K \\
y_{\max }=\frac{\pi}{2}(3+M \cos (x+n \theta))+K
\end{array}\right. \\
& C_{\text {min }}=\frac{I_{m d e}}{\pi f_{m d} V_{\text {ppripple }}} \\
& I_{m d e}=\sqrt{\sum_{n=-\infty}^{\infty} I_{c h}^{2}\left(n, m_{m d}\right)}
\end{aligned}
$$

where, $i_{c h}(n, m)$ is the capacitor's peak harmonic current at harmonic order $(m)$ and its side-bands $(n)$ around the inverter output fundamental frequency $f_{o}, i_{\text {linepeak }}$ is the peak output current of the inverter, $g$ is the number of groups, $N$ is the number of phases, $\phi$ is the phase shift between the fundamental output voltage and the fundamental output current of the inverter, $\theta$ is the electrical phase shift between the phases, $K$ is the interleaving angle, $m_{m d}=\frac{f_{m d}}{f_{s}}$ is the harmonic order of the capacitor's most dominant harmonic current component, $f_{s}$ is the switching frequency, $f_{m d}$ is the frequency of the capacitor's most dominant harmonic current component, $I_{m d e}$ is the capacitor's equivalent most dominant harmonic current, $V_{\text {ppripple }}$ is the peak to peak capacitor ripple voltage, $C_{\min }$ is the minimum required DC-link capacitance.

The film capacitor FB27A6J0335 from AVX with the specifications in Table IV is selected for the capacitor module.

As the ambient temperature inside an integrated drive is expected to be high, the calculation of the capacitor power 
TABLE III

DC-LINK CAPACITOR REQUIREMENTS FOR EACH PHASE CONNECTION

\begin{tabular}{|c|c|c|}
\hline Variable & Connection & Value \\
\hline \multirow{3}{*}{ Minimum rated voltage (V) } & $3-\phi$ & 400 \\
& $5-\phi$ & 240 \\
& $15-\phi$ & 80 \\
& $5 \times 3-\phi$ & 80 \\
& $3 \times 5-\phi$ & 80 \\
\hline \multirow{3}{*}{ Minimum ripple current rating (A) } & $3-\phi$ & 1.92 \\
& $5-\phi$ & 1.8 \\
& $5 \times 3-\phi$ & 1.75 \\
& $3 \times 5-\phi$ & 0.3 \\
& $3-\phi$ & 2 \\
\hline \multirow{3}{*}{ Minimum capacitance $(\mu \mathrm{F})$} & $5-\phi$ & 3.2 \\
& $15-\phi$ & 9.5 \\
& $5 \times 3-\phi$ & 0.5 \\
& $3 \times 5-\phi$ & 0.65 \\
\hline
\end{tabular}

TABLE IV

KEY SPECIFICATIONS OF THE SELECTED CAPACITOR MODULE

\begin{tabular}{|c|c|}
\hline Variable & Value \\
\hline rated voltage $(\mathrm{V})$ & 550 \\
rated rms ripple current $(\mathrm{A})$ & 5 \\
capacitance $(\mu \mathrm{F})$ & 3.3 \\
$\mathrm{ESR}(\mathrm{m} \Omega)$ & 22 \\
$\tan (\delta)$ & $2 \mathrm{e}-4$ \\
thermal resistance $R_{\text {th }}\left({ }^{\circ} \mathrm{C} / \mathrm{W}\right)$ & 27.3 \\
rated hotspot temperature $\left({ }^{\circ} \mathrm{C}\right)$ & 100 \\
$\mathrm{ESL}(\mathrm{nH})$ & 25 \\
\hline
\end{tabular}

loss and hot spot temperature is crucial. (5) can be used to calculate the power loss and the hot spot temperature of the capacitor. The worst case module capacitor loss is calculated to be $0.0814 \mathrm{~W}$ which means a temperature rise of $2.3{ }^{\circ} \mathrm{C}$ above the ambient. Note that this small loss results thanks to the modular construction of the drive that divides the DC-link current ripple over the capacitor modules.

$$
\begin{cases}P_{d} & =\frac{1}{2} C \tan (\delta) \sum_{m=1}^{\infty} \sum_{n=-\infty}^{\infty} V_{p p h}^{2} f_{h} \\ P_{t} & =\sum_{m=1}^{\infty} \sum_{n=-\infty}^{\infty} I_{c h r m s}^{2}(n, m) \times \\ & E S R(n, m) \\ \theta_{\text {hotspot }} & =\theta_{\text {ambient }}+\left(P_{d}+P_{t}\right) R_{t h}\end{cases}
$$

Here, $C$ is the value of the selected capacitance, $\tan (\delta)$ is the dielectric loss tangent, $V_{p p h}$ is the peak to peak ripple voltage resulting from the harmonic with frequency $\left(f_{h}\right)$, $I_{\text {chrms }}$ is the harmonic current rms value for one module capacitor, $E S R$ is the equivalent series resistance at the harmonic $(n, m), P_{d}$ is the dielectric loss component, $P_{t}$ is the loss in the ESR, $\theta_{\text {ambient }}$ is the maximum allowable ambient temperature, $\theta_{\text {hotspot }}$ is the maximum allowable ca-

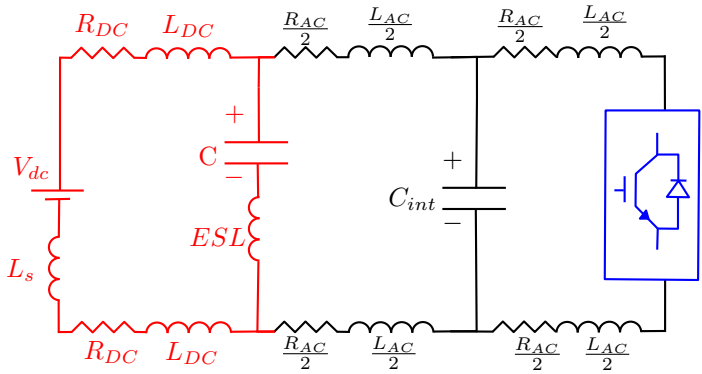

Fig. 11. Per module bus-bar equivalent circuit

pacitor hotspot temperature, $R_{t h}$ is the maximum thermal resistance of the capacitor from its hotspot to the ambient. $C, \tan (\delta), R_{t h}, E S R$ are all extracted from the datasheet of the selected capacitor.

\section{B. Electromagnetic analysis of the bus-bar}

The electromagnetic analysis is performed for two purposes. The first one is to evaluate the DC-link parasitics [17] so that, the electrical stresses over the bus-bar insulation and the converter switches can be evaluated. The second one is to evaluate the electromagnetic loss density distribution over the bus-bar due to the DC and the AC currents so that, the temperature distribution over the bus-bar can be evaluated.

1) Bus-bar parasitics and electrical stresses: Fig. 11 shows the per module equivalent circuit of the DC-link structure in Fig. 4. The values of the parasitic components of the DC-link structure are computed using electromagnetic FEM and listed in Table $\mathrm{V}$ as per module values. The values are computed for $1 \mathrm{~mm}$ thick copper and aluminium plates considering a $1 \mathrm{~mm}$ Kapton insulation layer. $L_{A C}$ is the plate parasitic inductance from the capacitor terminals to the converter module input terminals. $L_{A C}$ and $E S L$ constitute a part of the commutation loop inductance.

Due to the high transition speed of the GaN switches [9], any small parasitic inductance in the commutation loop contributes considerably to the voltage stress on the switches and the bus-bar insulation during turn-off transition of the switches. The switch voltage spike above the DC-link voltage can be estimated from (6). To illustrate the influence of the parasitics on the module terminals voltage stress, the circuit in Fig. 11 is simulated considering the three phase configuration of the drive and the dynamic model of the $\mathrm{GaN}$ switch GS66508B used in the implementation of the converter. Fig. 12 (left) shows the resulted converter module terminal voltage, a spike of $73 \mathrm{~V}$ above the $400 \mathrm{~V}$ DC voltage can be observed. Since the peak voltage is $473 \mathrm{~V}$, this can still be tolerated by the switches and the bus-bar insulation.

$$
\left\{\begin{array}{l}
V_{\text {spike }}=L_{\text {loop }} \frac{d i_{a}}{d t} \\
L_{\text {loop }}=2 L_{A C}+E S L+L_{P C B}
\end{array}\right.
$$

where, $V_{\text {spike }}$ is the switch spike voltage, $i_{a}$ is the transistor current during commutation, $L_{P C B}$ is the PCB inductance.

The influence of adding four $0.1 \mu \mathrm{F}$ ceramic capacitors close to the terminals of the converter module is shown in Fig. 12 
TABLE V

PER MOdULE BUS-BAR PARASITIC VALUES

\begin{tabular}{|c|c|c|}
\hline Plate material & Parameter & Value \\
\hline \multirow{5}{*}{ Copper } & $R_{D C}(m \Omega)$ & 1.125 \\
& $L_{D C}(n H)$ & 409 \\
& $R_{A C}(m \Omega)$ & 0.3 \\
& $L_{A C}(n H)$ & 16.04 \\
& $C_{i n t}(p F)$ & 36.08 \\
\hline \multirow{5}{*}{ Aluminium } & $R_{D C}(m \Omega)$ & 1.725 \\
& $L_{D C}(n H)$ & 409 \\
& $R_{A C}(m \Omega)$ & 0.3 \\
& $L_{A C}(n H)$ & 16.04 \\
& $C_{i n t}(p F)$ & 36.08 \\
\hline
\end{tabular}
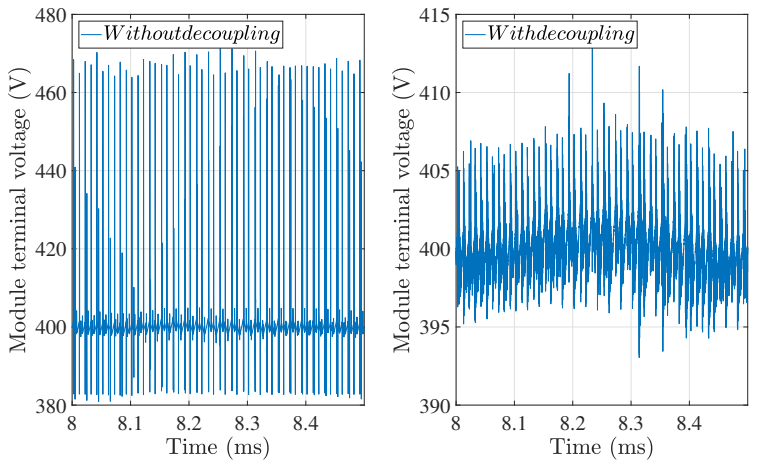

Fig. 12. The module terminal voltage spike due to the DC-link parasitics (left) and spike reduction by decoupling (right)
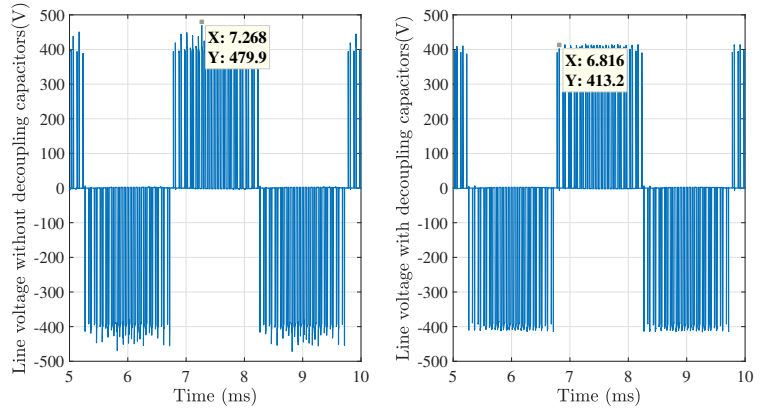

Fig. 13. The line voltage spike due to the DC-link parasitics (left) and spike reduction by decoupling (right)

(right). The additional capacitors reduce the voltage spike to $12 \mathrm{~V}$.

The effect of the parasitics on the line voltage with and without the decoupling capacitors is evaluated and reported in Fig. 13. It can be seen that the effect on the DC-link voltage waveform is directly reflected on the line voltage.

The effect of the parasitics on the phase voltage with and without the decoupling capacitors is evaluated and reported in Fig. 14. A smaller influence on the phase voltage spike can be noticed as it is affected by the transient switching behaviour of only one inverter leg. The decoupling capacitors are reducing the phase voltage spike by about $23 \mathrm{~V}$.
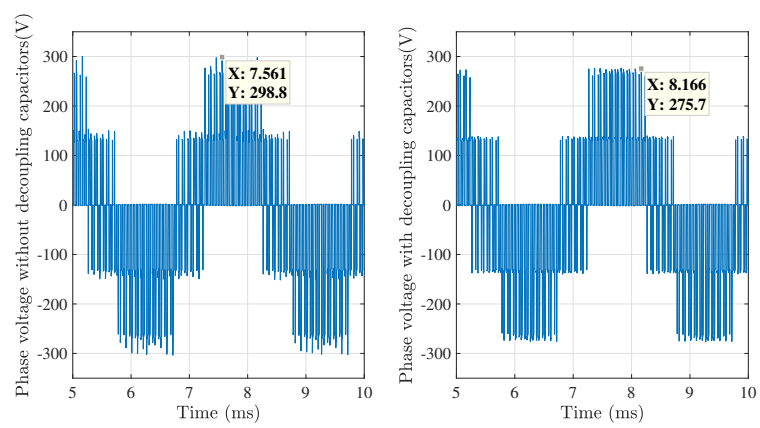

Fig. 14. The phase voltage spike due to the DC-link parasitics (left) and spike reduction by decoupling (right)

$L_{D C}$, computed as the total DC inductance seen between the DC input terminals multiplied by the number of modules, smooths the DC-source current which reduces the electrical and the thermal stresses on the DC-source. Note that the $L_{D C}$ is 25 times higher than $L_{A C}$ which is an advantage for the proposed DC-link structure. $C_{i n t}$ is the capacitance between the plates and it further smooths the inverter terminal voltage. $R_{A C}$ and $R_{D C}$ cause the power loss and the temperature rise of the bus-bar.

2) Bus-bar loss density distribution: The highest bus-bar loss occurs for the fifteen phase configuration with common neutral point due to the lowest DC-link voltage and the highest capacitor current. The loss in the bus-bar occurs due to the $\mathrm{DC}$ and the $\mathrm{AC}$ currents drawn from the DC-source and the capacitors. The DC-current $\left(I_{d c}\right)$ is computed from (7) considering $90 \%$ efficiency $(\eta)$ and the AC-current is computed from (4). The values of the DC and the AC currents are $236 \mathrm{~A}$ and $35 \mathrm{~A}$ respectively.

$$
I_{d c}=\frac{P_{r}}{\eta V_{d c}}
$$

where, $P_{r}$ is the rated drive power, $V_{d c}$ is the DC-link voltage.

Both the AC and the DC current are injected in the bus-bar and the loss density is evaluated in case of copper plates (Fig. 15) and aluminium plates (Fig. 16). It can be seen that the maximum loss density is located at the input DC tabs due to the higher DC current compared to the AC one and also the total DC-current of the fifteen modules is passing through the input tabs unlike the AC current that divides over the fifteen capacitors. The maximum loss density is 1.53 times higher in case of aluminium plates compared to copper plates due to the lower electrical conductivity of the aluminium.

\section{CFD analysis of the bus-bar}

A CFD model is built to evaluate the temperature of the bus-bar components to ensure that the insulation temperature is below its rated value given the high ambient temperature inside an integrated drive. Assuming an ambient temperature of $50^{\circ} \mathrm{C}$, natural air convection and the loss density distribution in Figs. 15 and 16, the temperature field is evaluated and shown in Figs. 17 and 18 for the plates and the insulation layer in case of copper and aluminium plates respectively. The thermal properties of the materials used in the simulation are 


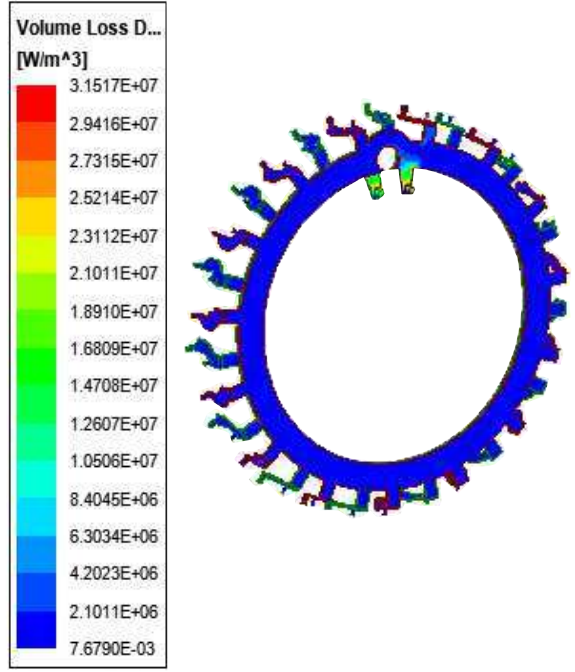

Fig. 15. The bus-bar loss density distribution due to the $A C$ and the $D C$ current in case of copper plates

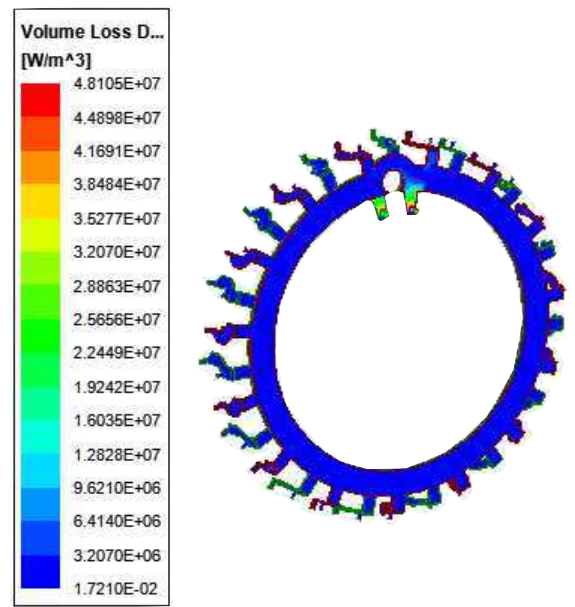

Fig. 16. The bus-bar loss density distribution due to the $A C$ and the $D C$ current in case of Aluminium plates

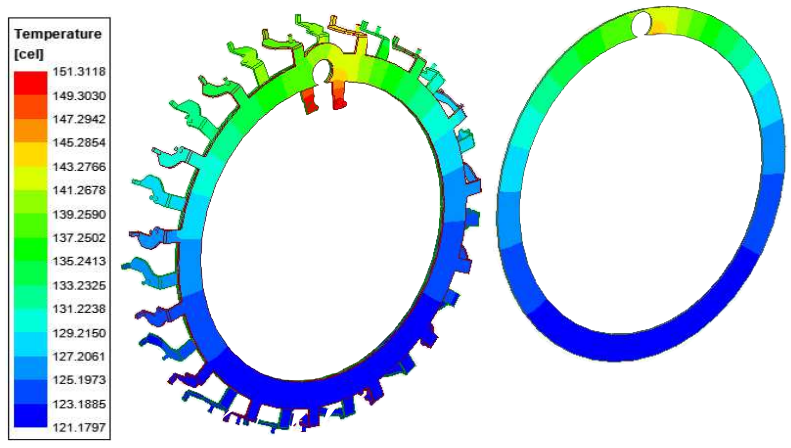

Fig. 17. The bus-bar temperature distribution in case of copper plates with plate temperature (left) and insulation temperature (right)

given in Table VI. Here, $\rho$ and $C_{p}$ are the mass density and the specific heat capacity respectively.

The insulation temperature rises $97.3^{\circ} \mathrm{C}$ and $165.8^{\circ} \mathrm{C}$ above the ambient for the copper and the aluminium plates respectively. For both materials, the insulation temperature stays

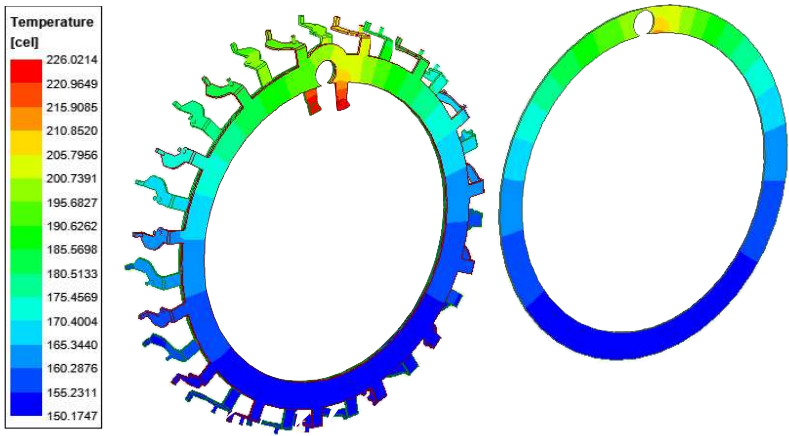

Fig. 18. The bus-bar temperature distribution in case of aluminium plates with plate temperature (left) and insulation temperature (right)

TABLE VI

THERMAL PROPERTIES OF THE BUS-BAR MATERIALS

\begin{tabular}{|c|c|c|c|}
\hline Material & $K_{t h}(\mathrm{~W} / \mathrm{m} . \mathrm{K})$ & $\rho\left(\mathrm{kg} / \mathrm{m}^{3}\right)$ & $C_{p}(\mathrm{~J} / \mathrm{kg} . \mathrm{K})$ \\
\hline Copper & 385 & 8890 & 392 \\
Aluminium & 167 & 2712 & 896 \\
Kapton & 0.4 & 1330 & 1420 \\
\hline
\end{tabular}

below the rated value of the Kapton material. The $68.5^{\circ} \mathrm{C}$ more temperature rise in case of aluminium plates is due to the higher loss density and the lower thermal conductivity of the aluminium. It can be seen also the higher temperature gradient in case of aluminium plates due to the lower thermal conductivity. The maximum insulation temperature is $15 \%$ and $28.5 \%$ higher than the average in case of copper and aluminium plates respectively.

\section{EXPERIMENTAL RESULTS}

The three teeth integrated setup shown in Fig. 19 is built to validate the design concepts. It consists of three $\mathrm{GaN}$ converter modules (Fig. 3), three stator teeth, an $R=11.5 \Omega, L=3 \mathrm{mH}$ load and a DC-link PCB. The line currents are measured with the on board current sensor ACHS-7123 while the capacitor currents are measured using the current probe TCPA300 with the static transfer function of $10 \mathrm{~A} / \mathrm{mV}$. All waveforms are visualized using a Tektronix $1 \mathrm{GHz}$ bandwidth scope. The sinusoidal PWM technique is utilized and the control pulses are generated using the dSPACE MicroLabBox. The three modules are operated as three phase inverter.

The capacitor current is measured at switching frequency $10 \mathrm{kHz}$, fundamental frequency of $50 \mathrm{~Hz}$, and three different peak line currents of 7.5 A, 5.5 A and 3.8 A to compare the measured rms value with the calculated value (4). With the value of the $R L$ load used and $50 \mathrm{~Hz}$, the resulting power factor is 0.997 near to unity to evaluate the worst case value [13]. Fig. 20 shows the measured three phase line currents in case of 7.5 A peak.

The capacitor current at $7.5 \mathrm{~A}$ peak line current is shown in Fig. 21 for ten power cycles and Fig. 22 for ten switching cycles. The measured and the calculated capacitor rms current at different peak line currents are reported in Table VII with the percentage error between them. 


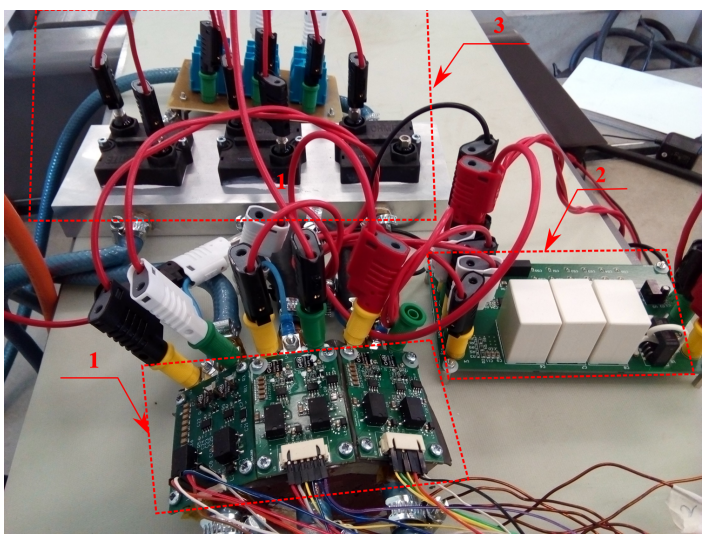

Fig. 19. Experimental setup: (1) The three teeth, (2) The DC link board, (3) The Load

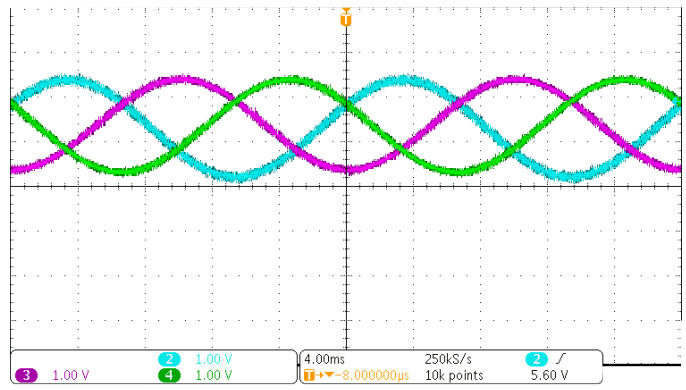

Fig. 20. The three phase currents with 7.5A peak

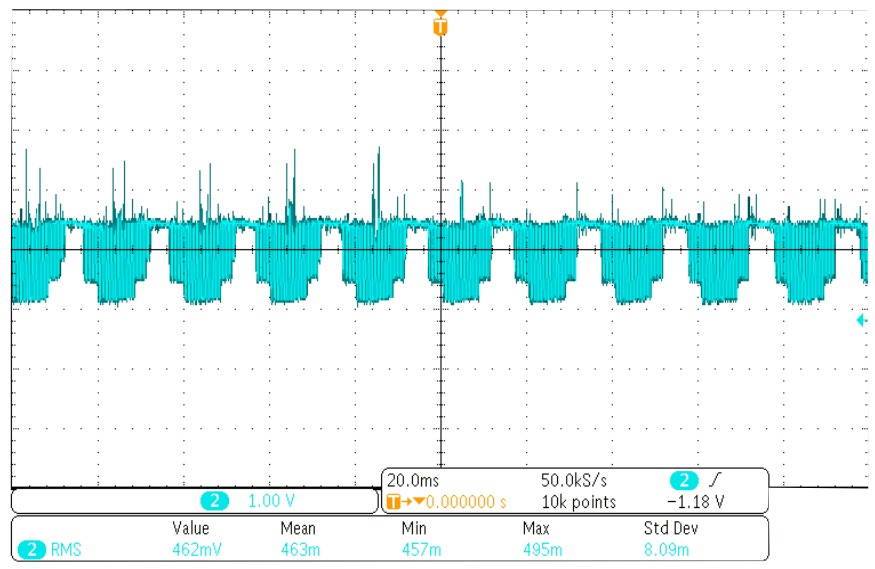

Fig. 21. The capacitor current for 10-power cycles

TABLE VII

CAPACITOR MEASURED AND CALCULATED RMS CURRENT

\begin{tabular}{|c|c|c|c|}
\hline \multirow{2}{*}{ Peak line current (A) } & \multicolumn{2}{|c|}{ capacitor rms current } & \multirow{2}{*}{ \% error } \\
\cline { 2 - 3 } & measured & calculated & \\
\hline 7.5 & 4.62 & 4.35 & -5.7 \\
5.5 & 3.41 & 3.2 & -6.1 \\
3.8 & 2.48 & 2.35 & -5.3 \\
\hline
\end{tabular}

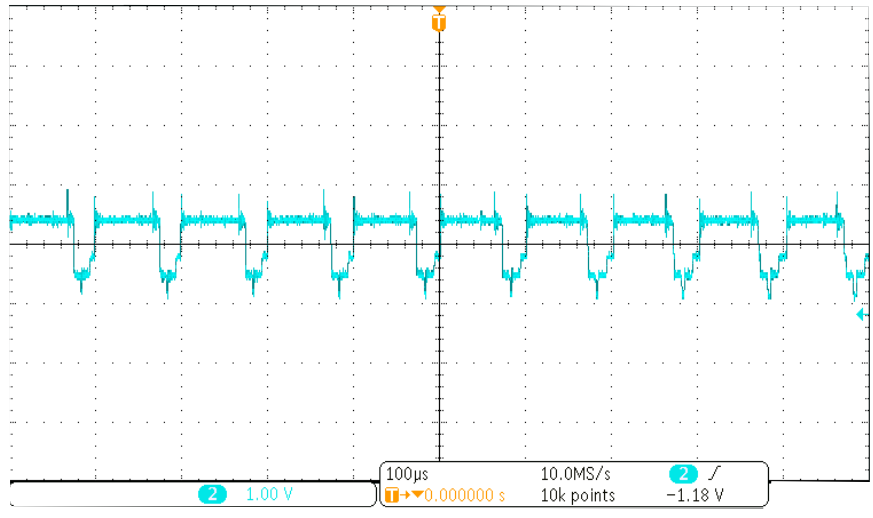

Fig. 22. The capacitor current for 10-switching cycles

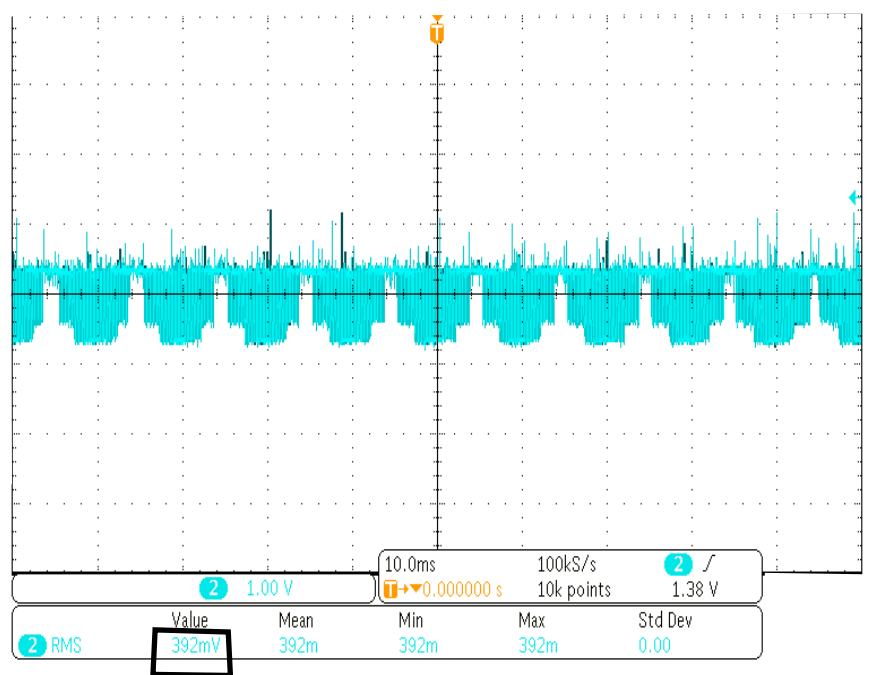

Fig. 23. The capacitor current at $10 \mathrm{kHz}$ switching frequency

The difference between the measured and the calculated current is mainly resulting from the influence of the parasitics and the decoupling capacitors.

The influence of the switching frequency on the capacitor current is visualized by measuring the capacitor current at a constant peak line current of $6.5 \mathrm{~A}$ and two different switching frequencies $(10 \mathrm{kHz}, 30 \mathrm{kHz})$. Fig. 23 shows the measured capacitor current at $10 \mathrm{kHz}$ and Fig. 24 at $30 \mathrm{kHz}$ with the rms value marked on the graph. A $20.6 \%$ increase in the capacitor rms current can be observed at $10 \mathrm{kHz}$. The reason of the decrease of the capacitor current with the increase in the switching frequency is the higher inductive impedance of the DC-link that further smooths the current at the higher switching frequency.

The estimation of the capacitor power loss using (5) is assessed by measuring the capacitor temperature at two different line currents $(5.5 \mathrm{~A}, 3.8 \mathrm{~A})$ and comparing the thermally measured power with the electrically calculated power. Both measurements are captured at ambient temperature of $25^{\circ} \mathrm{C}$ and free air convection. The capacitor is covered with a black tape for a better emissivity and temperature measurement accuracy. The resulted hot spot temperature is $36.7^{\circ} \mathrm{C}$ and $34.1^{\circ} \mathrm{C}$ for $5.5 \mathrm{~A}$ and $3.8 \mathrm{~A}$ peak line current respectively. 


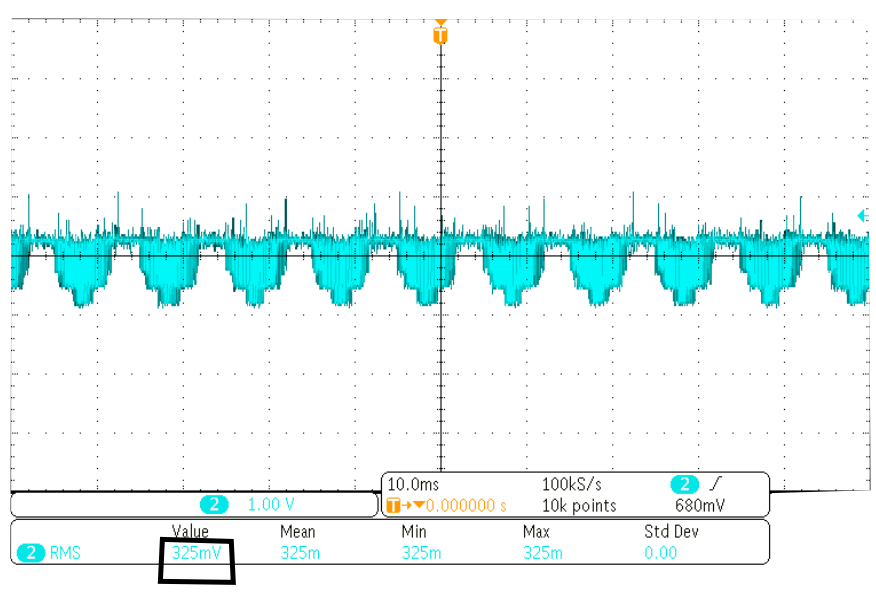

Fig. 24. The capacitor current at $30 \mathrm{kHz}$ switching frequency

TABLE VIII

CAPACITOR MEASURED AND CALCULATED LOSSES

\begin{tabular}{|c|c|c|c|}
\hline \multirow{2}{*}{ Peak line current (A) } & \multicolumn{2}{|c|}{ capacitor loss } & \multirow{2}{*}{ \% error } \\
\cline { 2 - 3 } & measured & calculated & \\
\hline 5.5 & 0.508 & 0.594 & 16.9 \\
3.8 & 0.3957 & 0.464 & 17.2 \\
\hline
\end{tabular}

Table VIII contains the capacitor power loss measured thermally and calculated electrically with the percentage difference between both of them. The difference between the measurements and the calculations can be explained as follows: The variation of the ESR and the thermal resistance of the capacitors with temperature is not given in the datasheet of the selected part instead, fixed values at $25^{\circ} \mathrm{C}$ are given. Neglecting the variation of these parameters with temperature introduces an error in the calculation of the capacitor losses. The capacitor temperature is measured with the thermal camera (GTC 400), the measured value has an error of $3^{\circ} \mathrm{C}$, this represents the measurement error. Since the measured capacitor temperature is less than $37^{\circ} \mathrm{C}$, the contribution of the thermal camera measurement error is expected to be the main reason of the discrepancy.

Fig. 25 shows the manufactured DC-link bus-bar installed on the stator of the integrated drive shown in Fig. 1. The bus-bar is manufactured from Aluminium of $1 \mathrm{~mm}$ thickness. The thermal performance of the bus-bar is tested by injecting $55 \mathrm{~A}$ (to limit the temperature of the wires connecting the DC-source to the bus-bar) in the DC-input tabs at ambient temperature of $25^{\circ} \mathrm{C}$ and the resulted temperature distribution is reported in Fig. 26. At such current, the bus-bar hot spot at the input tabs reaches $110^{\circ} \mathrm{C}$ much smaller than the rated value of the Kapton, an indication of the possibility to inject higher input current.

\section{CONCLUSION}

An integrated DC-link structure topology for reconfigurable modular motor drives is proposed and extensively analysed in this paper. The proposed topology has many advantages for the reconfigurable modular integrated drives. It combines both the

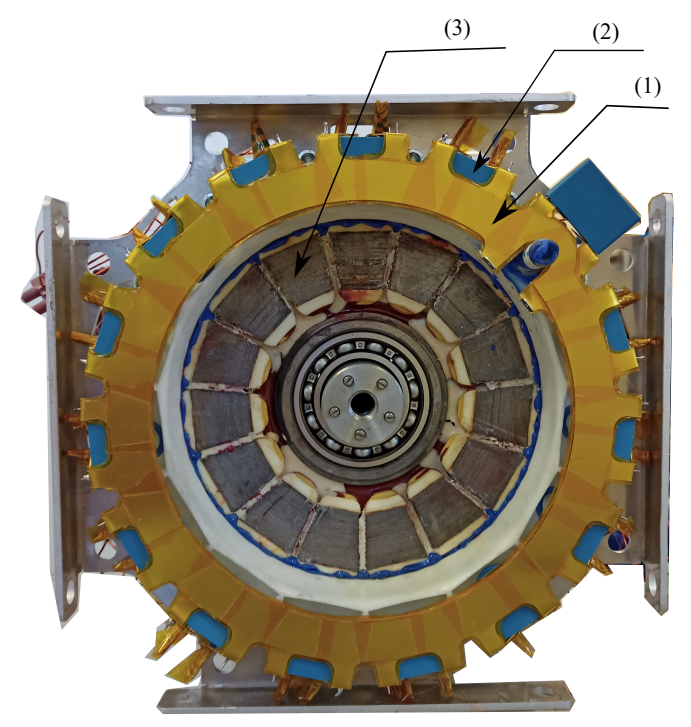

Fig. 25. The manufactured stator of the integrated drive with the bus-bar installed: (1) the DC-link bus-bar, (2) the DC-link capacitor, (3) the stator teeth

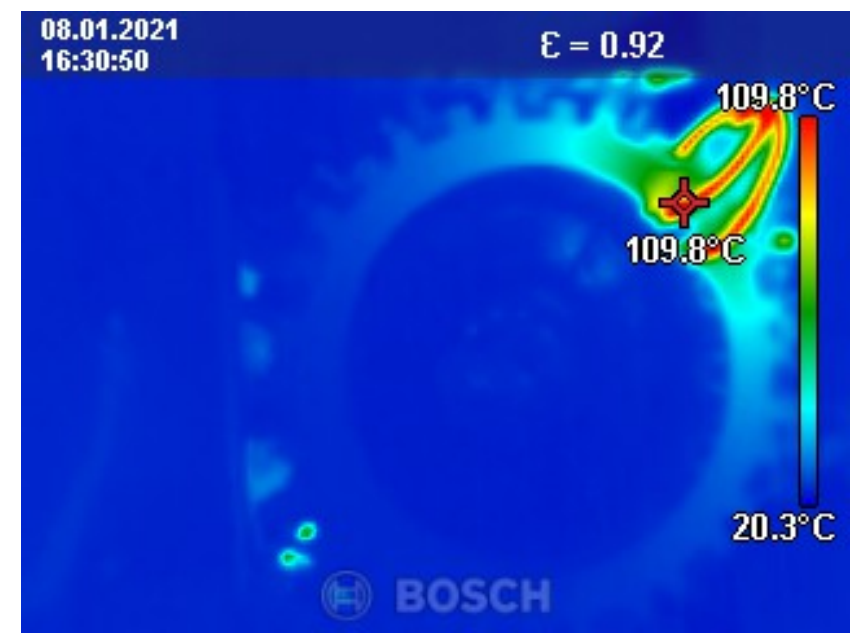

Fig. 26. The temperature distribution over the bus-bar measured at 55 A input DC-current

capacitors and the bus-bar together and integrates them with the modular integrated converter/machine structure without increasing the outer diameter of the integrated converter/machine set which enhances the compactness of the integrated drive. The per module AC parasitic inductance from the capacitor terminals to the inverter input terminals is calculated to be 16 $\mathrm{nH}$ which is a small value compared to the $E S L$ resulting in a small voltage stress on the switches. The per module DC parasitic inductance is also calculated to be $409 \mathrm{nH}$ which is a relatively high value resulting in a smoother DC-link current and hence, lower thermal stresses on the DC-source.

The proposed DC-link structure is designed for a fifteen phase reconfigurable circumscribing polygon integrated drive for all its possible configurations. Generic analytical equations for the design of the DC-link capacitors for any configuration are provided. Considering the high ambient temperature inside the integrated drive, the electromagnetic loss density distribu- 
tion of the bus-bar is computed and supplied to a CFD model to compute the bus-bar temperature. The calculated temperature is proven to be tolerable by the bus-bar components.

\section{REFERENCES}

[1] J. Wang, Y. Li, and Y. Han, "Integrated Modular Motor Drive Design With GaN Power FETs," IEEE Transactions on Industry Applications, vol. 51, DOI 10.1109/TIA.2015.2413380, no. 4, pp. 3198-3207, 2015.

[2] J. Wang, Y. Li, and Y. Han, "Evaluation and design for an integrated modular motor drive (IMMD) with GaN devices," 2013 IEEE Energy Conversion Congress and Exposition, ECCE 2013, DOI 10.1109/ECCE.2013.6647278, no. Immd, pp. 4318-4325, 2013.

[3] B. Ioana, R. Mircea, and S. Loránd, "Modular Electrical Machines â A Survey," no. 15 , pp. 6-11, 2015.

[4] N. R. Brown, T. M. Jahns, and R. D. Lorenz, "Power converter design for an integrated modular motor drive," Conference Record - IAS Annual Meeting (IEEE Industry Applications Society), DOI 10.1109/IAS.2007.205, pp. 1322-1328, 2007.

[5] M. Salcone and J. Bond, "Selecting film bus link capacitors for high performance inverter applications," 2009 IEEE International Electric Machines and Drives Conference, IEMDC '09, DOI 10.1109/IEMDC.2009.5075431, pp. 1692-1699, 2009.

[6] A. Tenconi, F. Profumo, S. E. Bauer, and M. D. Hennen, "Temperatures evaluation in an integrated motor drive for traction applications," IEEE Transactions on Industrial Electronics, vol. 55, DOI 10.1109/TIE.2008.2003099, no. 10, pp. 3619-3626, 2008.

[7] A. Morya, M. Moosavi, M. C. Gardner, and H. A. Toliyat, "Applications of Wide Bandgap (WBG) devices in AC electric drives: A technology status review," 2017 IEEE International Electric Machines and Drives Conference, IEMDC 2017, DOI 10.1109/IEMDC.2017.8002288, pp. 18, 2017.

[8] K. Shirabe, M. Swamy, J. K. Kang, M. Hisatsune, Y. Wu, D. Kebort, and J. Honea, "Advantages of high frequency PWM in AC motor drive applications," 2012 IEEE Energy Conversion Congress and Exposition, ECCE 2012, DOI 10.1109/ECCE.2012.6342519, pp. 2977-2984, 2012.

[9] W. Lee, S. Li, D. Han, B. Sarlioglu, T. A. Minav, and M. Pietola, "A Review of Integrated Motor Drive and Wide-Bandgap Power Electronics for High-Performance Electro-Hydrostatic Actuators," IEEE Transactions on Transportation Electrification, vol. 4, DOI 10.1109/TTE.2018.2853994, no. 3, pp. 684-693, 2018.

[10] A. H. Mohamed, H. Vansompel, P. Sergeant, and S. Member, "An Integrated Modular Motor Drive with Shared Cooling for Axial Flux Motor Drives," DOI 10.1109/TIE.2020.3028818, 2020.

[11] M. Maerz, E. Schimanek, and M. Billmann, "Towards an Integrated Drive for Hybrid Traction," no. September, pp. 3-7, 2008.

[12] X. Pei, W. Zhou, and Y. Kang, "Analysis and Calculation of DCLink Current and Voltage Ripples for Three-Phase Inverter With Unbalanced Load," IEEE Transactions on Power Electronics, vol. 30, DOI 10.1109/TPEL.2014.2375353, no. 10, pp. 5401-5412, 2015.

[13] J. Kolar and S. Round, "Analytical calculation of the RMS current stress on the DC-link capacitor of voltage-PWM converter systems," IEE Proceedings-Electric Power Applications, vol. 153, DOI 10.1049/ip-epa:20050458, no. 4, pp. 535-543, 2006. [Online]. Available: https://ieeexplore.ieee.org/document/1650869

[14] B. Rubey, A. Patzak, F. Bachheibl, and D. Gerling, "DC-link current harmonics minimization in ISCAD multi-phase inverters with interleaving," 2017 IEEE Vehicle Power and Propulsion Conference, VPPC 2017 - Proceedings, vol. 2018-Janua, DOI 10.1109/VPPC.2017.8330880, pp. 1-7, 2018.

[15] S. Bhattacharya, D. Mascarella, and G. Joos, "Interleaved SVPWM and DPWM for dual three-phase inverter-PMSM: An automotive application," 2014 IEEE Transportation Electrification Conference and Expo: Components, Systems, and Power Electronics - From Technology to Business and Public Policy, ITEC 2014, DOI 10.1109/itec.2014.6861785, 2014.

[17] J. M. Guichon, J. Aimé, J. L. Schanen, C. Martin, J. Roudet, E. Clavel, M. Arpillière, R. Pasterczyk, and Y. Le Floch, "Busbar design: How to spare nanohenries?" Conference Record - IAS Annual Meeting (IEEE Industry Applications Society), vol. 4, DOI 10.1109/IAS.2006.256790, pp. 1865-1869, 2006.
[16] M. Ugur and O. Keysan, "DC link capacitor optimization for integrated modular motor drives," IEEE International Symposium on Industrial Electronics, vol. i, DOI 10.1109/ISIE.2017.8001258, pp. 263-270, 2017.

[18] A. D. Callegaro, J. Guo, M. Eull, B. Danen, J. Gibson, M. Preindl, B. Bilgin, and A. Emadi, "Bus Bar Design for High-Power Inverters," IEEE Transactions on Power Electronics, vol. 33, DOI 10.1109/TPEL.2017.2691668, no. 3, pp. 2354-2367, 2018.

[19] S. Tiwari, O. M. Midtgård, and T. M. Undeland, "Design of low inductive busbar for fast switching $\mathrm{SiC}$ modules verified by 3D FEM calculations and laboratory measurements," 2016 IEEE 17th Workshop on Control and Modeling for Power Electronics, COMPEL 2016, DOI 10.1109/COMPEL.2016.7556689, 2016.

[20] Z. Wang and G. Chen, "Study on planar busbar regarding stray inductance minimization and oscillation suppression for high power converter," 1st International Conference on Sustainable Power Generation and Supply, SUPERGEN '09, DOI 10.1109/SUPERGEN.2009.5347993, 2009.

[21] R. J. Pasterczyk, C. Martin, J. M. Guichon, and J. L. Schanen, "Planar busbar optimization regarding current sharing and stray inductance minimization," 2005 European Conference on Power Electronics and Applications, vol. 2005, DOI 10.1109/epe.2005.219745, 2005.

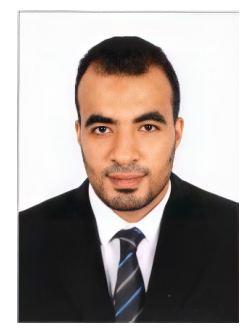

Abdalla $\mathbf{H}$. Mohamed received the MSc degree in electrical power and machines engineering from Cairo University, Cairo, Egypt, in 2016. Currently, he is working as a $\mathrm{PhD}$ researcher at Ghent University, Belgium. His research interests are design of integrated modular motor drives, Power converters , and multi-physics modelling of electrical machines.

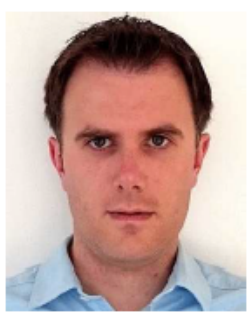

Hendrik Vansompel was born in Belgium in 1986. He received the MSc and $\mathrm{PhD}$ degrees in electromechanical engineering from Ghent University, Ghent, Belgium, in 2009 and 2013 respectively. He is currently a Postdoctoral Research Assistant with the Department of Electromechanical, Systems and Metal Engineering, Ghent University. His research interests include electric machines and power electronics.

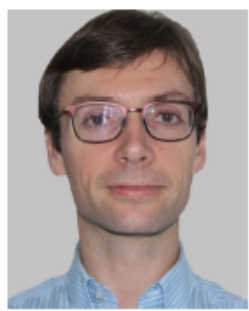

Peter Sergeant received the MSc degree in electromechanical engineering in 2001, and the $\mathrm{PhD}$ degree in electromechanical engineering in 2006, both from Ghent University, Ghent, Belgium. In 2006, he became a postdoctoral researcher at Ghent University (postdoctoral fellow of the Research Foundation - Flanders). Since 2012, he is associate professor at Ghent University. He is also core lab manager in the cluster Motion Products of Flanders Make. His research domain is electrical machines and drives for industrial and for sustainable energy applications. The focus is on accurate computation of losses in machines 